\title{
Levator Function in Blepharoptosis Surgery
}

\author{
Fadime Nuhoglu, MD $\quad$ Fatma Esin Ozdemir, MD $\quad$ Zeliha Karademir, MD ${ }^{1} \quad$ Kadir Eltutar, MD ${ }^{1}$ \\ ${ }^{1}$ Department of Ophthalmology, Istanbul Training and Research \\ Hospital, Istanbul, Turkey \\ Facial Plast Surg 2013;29:71-75. \begin{abstract}
MD, Department of Ophthalmology, Istanbul Training and Research Hospital, 34098, Istanbul, Turkey

(e-mail: drbnuhoglu@gmail.com; fadimenuhoglu@yahoo.com).
\end{abstract} \\ Address for correspondence and reprint requests Fadime Nuhoglu,
}

\begin{abstract}
Keywords

- aponeurotic blepharoptosis

- surgery

- treatment

- anterior levator resection

- levator function

Aim To investigate the predictive value of levator function in the outcomes of surgeries using the anterior levator resection technique in patients with aponeurotic blepharoptosis.

Methods A retrospective analysis of 69 eyes of 65 patients who underwent anterior levator resection between 2005 and 2011 in the ophthalmology department of a tertiary care center was performed. Levator function was assessed as perfect (10 to $15 \mathrm{~mm}$; group 1), good (9 to $10 \mathrm{~mm}$; group 2), and moderate (5 to $8 \mathrm{~mm}$; group 3). Postoperative success rates were analyzed with respect to preoperative levator function. Results The patient group consisted of 36 females (55.4\%) and 29 males (44.6\%) with a mean age of 57.2 (range: 16 to 71 ) years and average duration of follow-up of 13.7 (range: 6 to 36) months. The rates of success in the first, second, and third groups were $84.6 \%, 84 \%$, and $71 \%$, respectively. The success rate was found to be significantly lower in the third group $(p<0.05)$. The overall success rate, which was $78.3 \%$, improved to $87 \%$ after revision surgery.

Conclusion In patients with aponeurotic blepharoptosis with relatively better preoperative levator function, the anterior levator resection technique seems to yield more successful surgical outcomes. Preoperative assessment of levator function may help in the selection of appropriate treatment modality in these patients.
\end{abstract}

The function and efficacy of the upper eyelid plays a critical role in eye health. Ptosis is defined as the state of having an eyelid lower than normal. Ptosis may have many causes and its diagnosis and treatment may be complex and challenging. ${ }^{1}$

Blepharoptosis can be classified according to criteria such as age of onset, etiology, severity, and levator function (LF). ${ }^{2}$ Congenital ptosis develops due to dystrophy of the levator muscle, and it can be accompanied by lagophthalmos at downward gaze. ${ }^{1}$ Acquired blepharoptosis may result from myogenic, neurogenic, aponeurotic, mechanical, or traumatic causes (-Table 1). ${ }^{2}$ Congenital aponeurotic ptosis usually results from an anomaly in the fusion of a dystrophic levator muscle or the attachment of aponeurosis to tarsus. ${ }^{3}$ Acquired aponeurotic ptosis is the most common type of ptosis. It occurs due to the attenuation, dehiscence, or disinsertion of the levator aponeurosis from its normal insertion on the anterior inferior one-third of the tarsus. The most frequent causes of acquired aponeurotic ptosis are aging, chronic inflammation, use of rigid contact lenses, blunt trauma, and prior ophthalmic surgery. ${ }^{4}$

Recently, many advances emerging from a better understanding of the anatomy and physiology of the eyelid and orbit have occurred in ptosis surgery. ${ }^{5}$ Anterior levator resection is the standard approach used in patients with ptosis with a minimal $(4 \mathrm{~mm})$ function of the levator palpebrae superior muscle. ${ }^{6}$ The amount of levator to be resected at surgery is determined by preoperative factors like LF, degree of ptosis, and status of eye movements. ${ }^{7,8}$

We aimed to assess the predictive value of LF in the surgical outcomes of anterior levator resection technique in patients with aponeurotic blepharoptosis (AP).

\section{Materials and Methods}

This retrospective study was performed in the ophthalmology department of a tertiary care center. Levator resection
Issue Theme Aesthetic Treatment of the Eyelids and Midface; Guest Editors, Michael M. Kim, MD, and Tom D. Wang, MD, FACS
Copyright (c) 2013 by Thieme Medical Publishers, Inc., 333 Seventh Avenue, New York, NY 10001, USA. Tel: +1(212) 584-4662.
Dol http://dx.doi.org/ $10.1055 / \mathrm{s}-0033-1333835$. ISSN $0736-6825$. 
Table 1 Classification of acquired blepharoptosis with regard to etiopathogenesis

\begin{tabular}{|l|l|l|l|}
\hline Myogenic & Aponeurotic & Neurogenic & Traumatic \\
\hline Simple congenital ptosis & Congenital defect in the aponeurosis & Oculomotor palsy & \\
\hline Double elevator palsy & Acquired aponeurotic ptosis & Marcus Gunn jaw-winking syndrome & Horner's syndrome \\
\hline Myotonic dystrophy & & Myasthenia gravis & Apraxia of lid opening \\
\hline Blepharophimosis & & Blepharospasm & \\
\hline Congenital orbital fibrosis & & & \\
\hline Mitochondrial myopathy & & & \\
\hline $\begin{array}{l}\text { Chronic progressive external } \\
\text { ophthalmoplegia }\end{array}$ & & & \\
\hline Kearns-Sayre syndrome & & & \\
\hline $\begin{array}{l}\text { Mitochondrial myopathy, } \\
\text { strokelike episodes }\end{array}$ & & & \\
\hline $\begin{array}{l}\text { Mitochondrial encephalopathy } \\
\text { with ragged red fibers }\end{array}$ & & & \\
\hline $\begin{array}{l}\text { Oculopharyngeal muscular } \\
\text { dystrophy }\end{array}$ & & & \\
\hline $\begin{array}{l}\text { Facioscapulohumeral muscular } \\
\text { dystrophy }\end{array}$ & & & \\
\hline
\end{tabular}

performed on 69 eyelids of 65 patients between 2005 and 2011 were analyzed. Detailed history including ophthalmologic and systemic complaints was obtained from patients referring with ptosis. In all patients, preoperative visual acuity measurement, anterior and posterior segment examination, and assessment for strabismus and amblyopia were performed. A Schirmer's test was performed and cases with xerophthalmia were closely examined for ocular surface disease. The degree of ptosis, marginal reflex distance (MRD), and vertical distance between upper and lower eyelids were determined. The vertical interpalpebral fissure was measured at the widest point between the upper and lower eyelids. This measurement was performed with the patient fixating on a distant object at primary gaze. The MRD was defined as the distance from the upper eyelid margin to the corneal light reflex in primary position. The LF was estimated by measuring the upper eyelid excursion from downgaze to upgaze ignoring the frontalis muscle function. In unilateral ptosis, the amount of ptosis was defined as the difference between the heights of the two vertical lids. In bilateral ptosis, the difference between the measured vertical lid height from $9 \mathrm{~mm}$, which is assumed to be the normal lid height, was assigned as the amount of ptosis. LF was assessed as perfect (10 to $15 \mathrm{~mm}$; group 1), good (9 to $10 \mathrm{~mm}$; group 2), and moderate (5 to $8 \mathrm{~mm}$; group 3 ). Postoperative success rates were analyzed with respect to preoperative LF.

Patients without Bell's phenomenon, those with LF $<4 \mathrm{~mm}$ and ocular surface disease, as well as cases with poor LF or ptosis resulting from neurogenic, traumatic, myopathic, and mechanical causes and impairment of extraocular muscle function, were excluded from the study. Patients had been preoperatively informed about the possibility of a revision procedure. Pre- and postoperative photographs were obtained from all patients in frontal view at downward and upward gaze positions. In this purpose, a Nikon DSLR D5000 camera was used (Nikon Corporation, Tokyo, Japan). All the operations were performed by the same surgeon (F.N.).

\section{Surgical Technique}

After topical instillation of proparacaine drops, the upper lid was marked at the level of pupilla. Infiltrative local anesthesia was applied to the upper lid with lidocaine hydrogen chloride $(20 \mathrm{mg} / \mathrm{mL}$ ) and epinephrine hydrogen chloride $(0.0125 \mathrm{mg} /$ $\mathrm{mL})$. Traction was accomplished with a 5-0 silk suture in the upper lid marked at the level of pupilla. The tarsal plate was incised through a skin crease and dissected superiorly between the orbicularis muscle and septum. A transverse incision was made into the fine layers of connective tissue overlying the septum. The incision was gently deepened until the pressure on the lower lid pushed the preaponeurotic fat pad forward. A buttonhole was created through the remaining septal tissue to enter the preaponeurotic space. This plane was extended medially and laterally to expose the fat pad and the anterior part of the levator muscle. The preaponeurotic fat was gently retracted to allow the inspection of the levator muscle and to expose Whitnall's ligament lying transversely across the levator muscle just above the tarsal plate. The levator aponeurosis and Müller's muscle were detached from the superior border of the tarsal plate preserving the underlying conjunctiva. Hemostasis was accomplished with bipolar cauterization. The Müller's muscle and the overlying aponeurosis were dissected from the conjunctiva to the level of the conjunctival fornix. A 6-0 absorbable suture was placed in the center of the aponeurosis (or levator muscle) to allow the appropriate resection and attachment to the tarsus. The height of the lid was adjusted with respect to the position of the suture. During the operation, the patient was evaluated 
while sitting at primary gaze position. Medial and lateral sutures were placed to achieve a satisfactory lid margin curve. We closed the skin with 6-0 Vicryl (Ethicon, LLC., San Lorenzo, CA) sutures, which were attached to the aponeurosis at the level of the closure. Frost suture was applied and ice compression was performed to reduce edema and hemorrhage postoperatively. Oral and topical antibiotics and oral analgesics were administered routinely for 1 week postoperatively. Frost suture was removed after 48 hours, and control visits were performed at the second day and first week, first, third, and sixth months (-Figs. 1, 2).

Achievement of a regular lid contour, complete correction of ptosis, or a residual ptosis $<1 \mathrm{~mm}$ and cases where the MRD is between 3.5 and $4.5 \mathrm{~mm}$ were considered as success.

\section{Statistical Analysis}

Statistical Package for Social Sciences (SPSS Inc., Chicago, IL) for Windows 10.0 was used for statistical analysis. Mann-Whitney $U$ and chi-square tests were utilized in the comparison of quantitative data. Results were evaluated with a $95 \%$ confidence interval and $p$ value $<0.05$ was considered significant.

\section{Results}

The patient group consisted of 36 females (55.4\%) and 29 males (44.6\%) with a mean age of 57.2 (range: 16 to 71 ) years. Sixty-one patients had unilateral ptosis whereas four cases suffered from bilateral ptosis (-Table $\mathbf{2}$ ). The mean duration of follow-up was 13.7 (range: 6 to 36) months. Data regarding the degree of ptosis and LF in the pre- and postoperative period is demonstrated in - Table 3 and - Table 4 .

Congenital and acquired types of AP existed in 23 (33.3\%) and $46(66.7 \%)$ cases. In acquired cases, operative trauma (27.6\%), senility (18.8\%), trauma (17.4\%), and chronic inflammation $(2.9 \%)$ were the leading presumable causes.

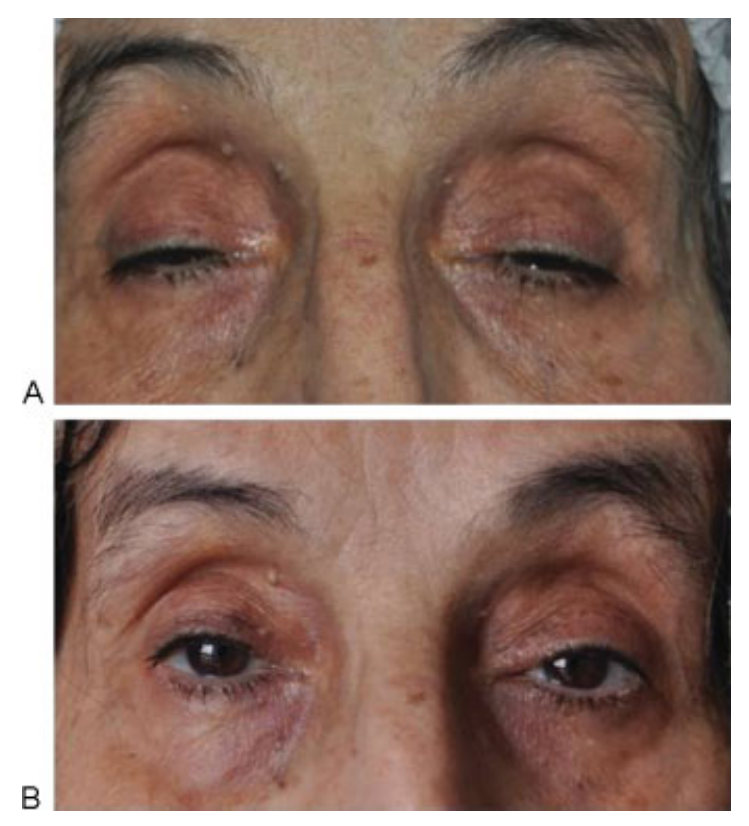

Fig. 1 (A) Preoperative view of bilateral senile aponeurotic ptosis; (B) 7-month postoperative view of the same patient.

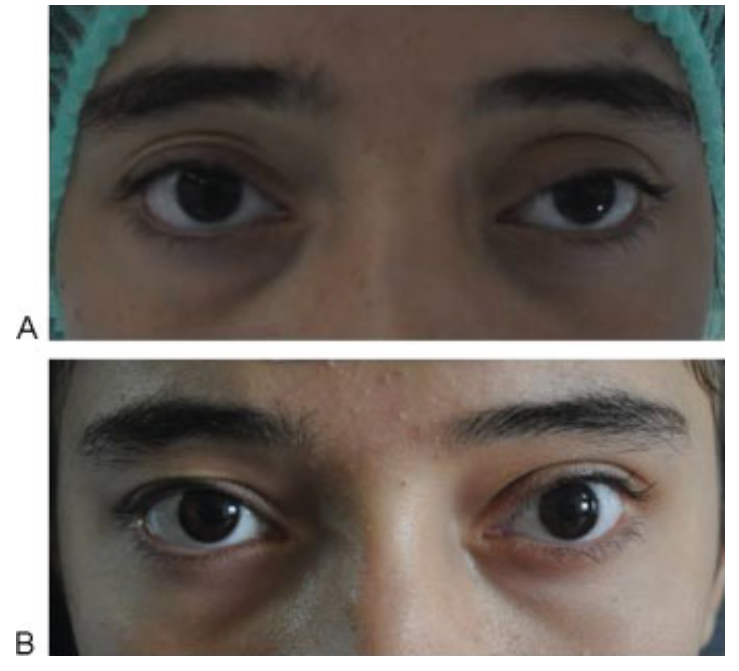

Fig. 2 (A) Preoperative view of left congenital aponeurotic ptosis; (B) 7-month postoperative view of the same patient.

In the first group with excellent LF, the rate of success was estimated as $84.6 \%$. Revision surgery improved this rate to 92.3\%. In the second group with good LF, the rate of success was $84 \%$. Revision intervention resulted in an increase of this rate to $92 \%$. Success rate achieved in the third group with moderate $\mathrm{LF}$ was $71 \%$. After revision, this rate was found to be $80.6 \%$. Comparison of success rates in three groups demonstrated that it was found to be significantly lower in the third group $(p<0.05)$.

Overall success rates after the initial intervention and revision surgery were found to be $78.3 \%$ and $87 \%$, respectively. No complications like keratitis, lagophthalmos, hemorrhage, and infection were encountered in the postoperative followup.

\section{Discussion}

Ptosis creates both functional and aesthetic problems for the patient. Patients presenting with symptomatic and involutional AP often require surgical repair. Detailed preoperative evaluation of the patient and familiarity with lid anatomy are important factors that may increase the success of surgical intervention. Approaches such as an anterior repair involving levator aponeurotic advancement, tarsoaponeurectomy, and posterior repair involving resection of Müller's muscle have proven effective for most acquired blepharoptosis correction. ${ }^{9}$

AP is the most common form of blepharoptosis that is usually associated with good LF. Elderly people are more vulnerable because the levator aponeurosis loosely attaches or detaches from the tarsus. The function of the levator muscle is mostly preserved. Levator advancement for the repair of aponeurotic ptosis may be used for all circumstances where adequate LF exists. Fibrous web bands between levator aponeurosis and orbital fat may restrict the movement of the levator aponeurosis and lead to limitation of eye opening. Subclinical and mild blepharoptoses may be corrected via releasing these fibrous bands without manipulation of the 
74 Levator Function in Blepharoptosis Surgery Nuhoglu et al.

Table 2 Demographic data of the patients comprising the three groups

\begin{tabular}{|c|c|c|c|c|c|c|}
\hline \multirow[t]{2}{*}{ Group } & \multirow[t]{2}{*}{ Age (mean) } & \multicolumn{2}{|c|}{ Gender } & \multicolumn{3}{|c|}{ Eye } \\
\hline & & Male & Female & Right & Left & Bilateral \\
\hline 1 & 45.3 & 5 & 8 & 7 & 5 & 1 \\
\hline 2 & 52.6 & 12 & 13 & 10 & 14 & 1 \\
\hline 3 & 55.7 & 12 & 15 & 14 & 11 & 2 \\
\hline
\end{tabular}

Table 3 Pre- and postoperative degree of ptosis in the three groups

\begin{tabular}{|l|l|l|}
\hline Group & $\begin{array}{l}\text { Preoperative degree } \\
\text { of ptosis }(\mathrm{mm})\end{array}$ & $\begin{array}{l}\text { Postoperative degree } \\
\text { of ptosis }(\mathrm{mm})\end{array}$ \\
\hline 1 & 2.2 & 0.3 \\
\hline 2 & 2.8 & 0.7 \\
\hline 3 & 3.1 & 1.75 \\
\hline
\end{tabular}

Müller muscle or the levator aponeurosis. This technique has been shown to be practical and highly effective in the correction of mild ptosis. ${ }^{10}$

Repair of blepharoptosis may provide significant improvement in vision and quality of life. Preoperative indicators of improvement were reported as MRD $\leq 2 \mathrm{~mm}$, superior visual field loss of at least 12 degrees or $24 \%$, downgaze ptosis impairing close-work activities, a chin-up backward head tilt due to visual axis obscuration, eye discomfort, or strain due to droopy lids and central visual interference. ${ }^{11}$ Preoperative measurements of upper eyelid heights may help in determining the amount of skin excision required in blepharoplasty for senile ptosis. ${ }^{4}$

In this series of patients with ptosis, the preoperative LF was found to be a predictive value for the surgical outcome. Undercorrection was encountered more commonly in patients with relatively poor LF. In contrast, the amount of LF was markedly higher in the overcorrected group. Even though this finding is noteworthy, it is insufficient for establishment of a direct relationship between preoperative LF and surgical outcome. In this aspect, prospective controlled trials may help for more healthy interpretations.

Interestingly, the degree of ptosis seems not to affect the surgical outcome. The importance of the LF in determining the success rate in our series is consistent with the findings of Jordan and Anderson. These authors have demonstrated that diminished LF was associated with late undercorrections. ${ }^{9}$

Table 4 Distribution of cases with respect to levator function

\begin{tabular}{|l|l|l|}
\hline Group & Levator function (LF) & $\begin{array}{l}\text { No. (\%) of } \\
\text { cases }\end{array}$ \\
\hline 1 & Excellent $(10 \mathrm{~mm}<\mathrm{LF}<15 \mathrm{~mm})$ & $13(18.8 \%)$ \\
\hline 2 & Good $(8 \mathrm{~mm}<\mathrm{LF}<10 \mathrm{~mm})$ & $25(36.2 \%)$ \\
\hline 3 & Moderate $(5 \mathrm{~mm}<\mathrm{LF}<8 \mathrm{~mm})$ & $31(45 \%)$ \\
\hline
\end{tabular}

In our series, the most common cause of failure was undercorrection (19\% at 6-month follow-up) rather than overcorrection (7\% at 6-month follow-up), indicating that the amount of levator resection must be planned carefully. Overcorrection carries a higher rate of risk for complications, but this must not deter the surgeon from aiming to correct the ptosis precisely. ${ }^{12-14}$ We think that levator resection has a higher rate of success and fewer complications in the surgical treatment of congenital and acquired upper lid ptosis with fair to good LF. Reoperation turns out to be effective in most cases in which levator resection has been performed.

In Abrishami et al's series, the overall success rate after the first operation was reported to be $78.7 \% .^{7}$ The most common complication after the first operation was undercorrection (19.1\%), which occurred more frequently among young patients. Lid fissure and MRD were found to increase after levator resection, but parameters like age, gender, type of ptosis, amblyopia, LF, and MRD were found to be not predictive for surgical outcomes of levator resection. ${ }^{7}$

We suggest that levator surgery with an anterior approach is a valuable method in ptosis surgery because not only is the exposure is better, but it also inflicts less harm on anatomic structures, allowing an easier resection.

\section{Conclusion}

Overall, we suggest that the anterior levator resection technique may provide better therapeutic outcomes in patients with AP with relatively good preoperative LF. Hence, preoperative assessment of LF can guide surgeons in determination of the appropriate surgical strategy in the management of blepharoptosis.

\section{References}

1 DiFrancesco LM, Codner MA, McCord CD. Upper eyelid reconstruction. Plast Reconstr Surg 2004;114:98e-107e

2 Dortzbach RK, Sutula FC. Involutional blepharoptosis. A histopathological study. Arch Ophthalmol 1980;98:2045-2049

3 Lemagne JM. Idiopathic aponeurotic ptozis in young adults. Orbit 1994;13:179-182

4 Maegawa J, Kobayashi S, Yabuki Y, Hirotomi K, Yasumura K, Iwai T. Blepharoplasty in senile blepharoptosis: preoperative measurements and design for skin excision. Aesthet Surg J 2012;32: 441-446

5 Anderson RL, Beard C. The levator aponeurosis. Attachments and their clinical significance. Arch Ophthalmol 1977;95:1437-1441

6 Beard C. The surgical treatment of blepharoptosis: a quantitative approach. Trans Am Ophthalmol Soc 1966;64:401-487 
7 Abrishami A, Bagheri A, Salour H, Aletaha M, Yazdani S. Outcomes of levator resection at tertiary eye care center in Iran: a 10-year experience. Korean J Ophthalmol 2012;26:1-5

8 Chang S, Lehrman C, Itani K, Rohrich RJ. A systematic review of comparison of upper eyelid involutional ptosis repair techniques: efficacy and complication rates. Plast Reconstr Surg 2012;129: 149-157

9 Jordan DR, Anderson RL. The aponeurotic approach to congenital ptosis. Ophthalmic Surg 1990;21:237-244

$10 \mathrm{Kim}$ JH, Lee IJ, Park MC, Lim H, Lee SH. Aesthetic blepharoptosis correction with release of fibrous web bands between the levator aponeurosis and orbital fat. J Craniofac Surg 2012;23:e52-e55
11 Cahill KV, Bradley EA, Meyer DR, et al. Functional indications for upper eyelid ptosis and blepharoplasty surgery: a report by the American Academy of Ophthalmology. Ophthalmology 2011;118: 2510-2517

12 Cates CA, Tyers AG. Outcomes of anterior levator resection in congenital blepharoptosis. Eye (Lond) 2001;15(Pt 6):770-773

13 Shore JW, Bergin DJ, Garrett SN. Results of blepharoptosis surgery with early postoperative adjustment. Ophthalmology 1990;97: 1502-1511

14 Lee IJ, Park MC, Lim H, Kim JH, Lee SH. Blepharoptosis correction: repositioning the levator aponeurosis. J Craniofac Surg 2011;22: $2284-2287$ 